\title{
RESEARCH
}

Open Access

\section{The clinical and mutational spectrum of B3GAT3 linkeropathy: two case reports and literature review}

\author{
Marlies Colman ${ }^{1}$, Tim Van Damme ${ }^{1}$, Elisabeth Steichen-Gersdorf ${ }^{2}$, Franco Laccone ${ }^{3}$, Sheela Nampoothiri ${ }^{4}$, \\ Delfien Syx ${ }^{1}$, Brecht Guillemyn ${ }^{1}$, Sofie Symoens ${ }^{1}$ and Fransiska Malfait ${ }^{1 *}$
}

\begin{abstract}
Background: Proteoglycans are large and structurally complex macromolecules which can be found in abundancy in the extracellular matrix and on the surface of all animal cells. Mutations in the genes encoding the enzymes responsible for the formation of the tetrasaccharide linker region between the proteoglycan core protein and the glycosaminoglycan side chains lead to a spectrum of severe and overlapping autosomal recessive connective tissue disorders, collectively coined the 'glycosaminoglycan linkeropathies'.

Results: We report the clinical findings of two novel patients with a complex linkeropathy due to biallelic mutations in B3GAT3, the gene that encodes glucuronosyltransferase I, which catalyzes the addition of the ultimate saccharide to the linker region. We identified a previously reported c.667G $>$ A missense mutation and an unreported homozygous c.416C > T missense mutation. We also performed a genotype and phenotype-oriented literature overview of all hitherto reported patients harbouring B3GAT3 mutations. A total of 23 patients from 10 families harbouring bi-allelic mutations and one patient with a heterozygeous splice-site mutation in B3GAT3 have been reported. They all display a complex phenotype characterized by consistent presence of skeletal dysplasia (including short stature, kyphosis, scoliosis and deformity of the long bones), facial dysmorphology, and spatulate distal phalanges. More variably present are cardiac defects, joint hypermobility, joint dislocations/contractures and fractures. Seven different B3GAT3 mutations have been reported, and although the number of patients is still limited, some phenotype-genotype correlations start to emerge. The more severe phenotypes seem to have mutations located in the substrate acceptor subdomain of the catalytic domain of the glucuronosyltransferase I protein while more mildly affected phenotypes seem to have mutations in the NTP-sugar donor substrate binding subdomain.
\end{abstract}

Conclusions: Loss-of-function mutations in B3GAT3 are associated with a complex connective tissue phenotype characterized by disproportionate short stature, skeletal dysplasia, facial dysmorphism, spatulate distal phalanges and -to a lesser extent- joint contractures, joint hypermobility with dislocations, cardiac defects and bone fragility. Based on the limited number of reported patients, some genotype-phenotype correlations start to emerge.

Keywords: Connective tissue, Glycosaminoglycans, GAG Linkeropathies, B3GAT3, Genotype, Phenotype

\footnotetext{
*Correspondence: Fransiska.Malfait@uGent.be

${ }^{1}$ Center for Medical Genetics, Ghent University and Ghent University Hospital,

0K5, Corneel Heymanslaan 10, B-9000 Ghent, Belgium

Full list of author information is available at the end of the article
}

(c) The Author(s). 2019 Open Access This article is distributed under the terms of the Creative Commons Attribution 4.0 International License (http://creativecommons.org/licenses/by/4.0/), which permits unrestricted use, distribution, and reproduction in any medium, provided you give appropriate credit to the original author(s) and the source, provide a link to the Creative Commons license, and indicate if changes were made. The Creative Commons Public Domain Dedication waiver (http://creativecommons.org/publicdomain/zero/1.0/) applies to the data made available in this article, unless otherwise stated. 


\section{Background}

Proteoglycans (PG) are large and structurally complex macromolecules which can be found in abundancy in the extracellular matrix and on the surface of all animal cells. PG are involved in a wide variety of functions such as cell-cell communication, cell-matrix interactions and cell growth and differentiation. PGs consist of a core protein with one or multiple glycosaminoglycan (GAG) sidechains covalently attached to it. GAGs are composed of repeating disaccharides consisting of an amino sugar ( $\mathrm{N}$-acetylglucosamine [GlcNAc] or N-acetylgalactosamine [GalNAc]) and an uronic acid (glucuronic [GlcA] or iduronic acid [IdoA]). The PG superfamily is subdivided into two major groups: heparan sulfate (HS) and chondroitin sulfate (CS)/dermatan sulfate (DS) PGs [1-3]. Before the polymerization of these HS and CS/DS chains, the synthesis of a linker region consisting of four saccharides is obligatory. This is a stepwise process requiring the coordinated action of specific transferases. First, a xylose unit is transferred onto a serine residue of the core protein by xylosyltransferase s I/II (encoded by XYLT1 and XYLT2), followed by the addition of two galactose units by galactosyltransferase I ( $\beta 4 \mathrm{GalT7}$, encoded by B4GALT7) and galactosyltransferase II ( $\beta 3 \mathrm{GalT6}$, encoded by B3GALT6), respectively. The formation of the linker region is completed by the transfer of glucuronic acid catalysed by glucuronosyltransferase I (GlcAT-I, encoded by B3GAT3) [4-9].

Biallelic mutations in all genes encoding these linker region enzymes have been identified, leading to a spectrum of overlapping autosomal recessive multisystemic disorders, the 'GAG linkeropathies' [10]. Mutations in XYLT1 were reported in patients with short stature, intellectual disability, flat face and subsequently, XYLT1 mutations were identified in patients with Desbuquois dysplasia type 2 (OMIM \#615777) [11-16]. Deficiency of XYLT2 causes a spondyloocular syndrome (OMIM \#605822) with eye and heart defects, hearing loss, fractures and learning problems [17-22]. B4GALT7 mutations are associated with a rare subtype of the Ehlers-Danlos syndrome (EDS), spondylodysplastic EDS (B4GALT7-spEDS; OMIM \#130070), characterized by short stature, joint hypermobility, hyperelastic skin, osteopenia and ocular problems [23-28]. A specific homozygous B4GALT7 mutation, c.808C > T p.(Arg270Cys), is associated with the Larsen of Reunion Island syndrome, characterized by severe joint hypermobility with dislocations [29]. Biallelic mutations in B3GALT6 also cause a spectrum of overlapping disorders. Malfait et al. [30] described a subtype of EDS (spondylodysplastic EDS, B3GALT6-spEDS) with skin fragility, delayed wound healing, joint laxity/contractures, intellectual disability and spondyloepimetaphyseal dysplasia, whereas Nakajima et al. [10] described a group of individuals suffering from spondyloepimetaphyseal dysplasia with joint laxity type 1 (SEMD-JL1; OMIM \# 271640). Van Damme et al. [31] expanded the spectrum of
B3GALT6-spEDS with cardiac defects, cervical spine instability, respiratory insufficiency and cerebrovascular accidents. Baasanjav et al. [32] reported the first biallelic B3GAT3 mutations in a consanguineous family and hitherto, B3GAT3 mutations have been reported in 24 patients from 11 families, all displaying multisystemic conditions characterized by craniofacial, cardiovascular and skeletal abnormalities [32-39].

Here, we report the clinical and molecular findings in two new independent patients with biallelic B3GAT3 mutations and we provide a literature overview of the genetic and phenotypic findings in all hitherto reported B3GAT3 patients. We also performed structural modelling of the reported missense mutations in B3GAT3 to investigate possible genotype-phenotype correlations. Our findings contribute to a better knowledge on the genotypic and phenotypic spectrum of B3GAT3-related disease and its delineation from the other linkeropathies.

\section{Results}

\section{Review of literature}

Mutations in B3GAT3 are extremely rare, with only 23 reported patients from 10 families harboring biallelic B3GAT3 mutations and one patient with a heterozygous B3GAT3 mutation [32-39]. Consistent clinical findings in patients with biallelic B3GAT3 mutations are: skeletal dysplasia (present in all) with shortening and bowing of long bones, (kypho)scoliosis, foot deformity and radioulnar synostosis; disproportionate short stature (16/21, mentioned in 21 of 23 the cases); spatulate distal phalanges (14/15), and facial dysmorphism, present in all patients, albeit with some variability. Characteristic craniofacial features include abnormalities in cephalic index (brachycephaly and dolichocephaly), frontal bossing, hypertelorism, prominent eyes, downslanting palpebral fissures, midface hypoplasia, depressed nasal bridge, microstomia and short neck. Two individuals presented with blue sclerae. Common findings, present in many but not all patients $(>60 \%)$, include dislocations of large joints (17/23), contractures of mostly the elbow joint (10/15) and structural cardiac defects, including septal defects and valve abnormalities (12/18). A number of features is more variably present $(<60 \%)$. Multiple fractures were reported in 7 patients and joint hypermobility was noted in 8 individuals. Skin involvement is uncommon, with hyperextensible skin, cutis laxa and excessive wrinkling on the palms of the hands, each reported only once $[33,36,38]$. Ocular problems are rare (only present in 3 patients) and diverse, including glaucoma, hyperopia, esotropia, amblyopia and astigmatism [36-38]. Intellectual disability was noted in 2 patients, one of which had multiple brain infarctions and subdural hematomas [37]. Since at least 9 of the families are consanguineous, some rare features are possibly not linked to the B3GAT3 mutations, but to another homozygous variant. Bloor et al. [34] reported 
the first patient harbouring a heterozygous splice-site mutation in B3GAT3. This patient clearly shared some clinical features associated with biallelic B3GAT3 mutations, but she also displayed some unique features, including a posterior cloaca, growth hormone deficiency with good response to therapy and sensorineural hearing loss. It is currently not clear whether all these symptoms are related to the B3GAT3 mutation. We summarized the clinical features in Table 1.

\section{Case reports \\ Patient 1}

Patient 1 is an Indian boy and third child from a thirddegree consanguineous marriage. His parents and two older siblings were reportedly healthy. His birth length was $46 \mathrm{~cm}(<\mathrm{P} 3)$, birth weight $2600 \mathrm{~kg}$ (P5-P10), and the occipitofrontal circumference $37 \mathrm{~cm}$ (P75). He had a large anterior fontanel, which communicated with the posterior fontanel. At the moment of examination 19 days after birth (Fig. 1), he had contractures of both large and small joints (including bilateral talipes equinovarus, flexion contractures of elbows, hips and knees), broad tips of fingers and toes, adducted thumbs and long fingers with camptodactyly of digits $3-5$ of the left and digit 5 of the right hand. In addition, he had a short neck and a severely asymmetrical thoracic cage with bulging of the left thoracic side. His skin was cutis laxa-like with excess skin folds, especially over the dorsum of hands and feet and the frontal region. He also displayed severe facial dysmorphic features such as dolichocephaly, hypertelorism, large eyes, downslanting palpebral fissures, lagophtalmos of the lower eye lids, blue sclerae, a pug nose, low-set and dysplastic ears and microstomia with a high-arched palate. Ophthalmological examination revealed bilateral corneal clouding with sclerocornea in the upper parts. His radiographs showed gracile long bones with a thin cortex and multiple fractures and some wormian bones in the occipital region. There was no cardiovascular involvement. $\mathrm{He}$ died at the age of 2.5 months because of an unknown reason. No autopsy was performed.

\section{Patient 2}

Patient 2 is a Turkish girl, the first child of consanguineous parents. She was born at 37 weeks of gestation with a birth weight of $2140 \mathrm{~g}$ and length of $43 \mathrm{~cm}$ (both $<\mathrm{P} 3$ ). Final height was $129,5 \mathrm{~cm}(-5,3$ SDS) with a weight of $37 \mathrm{~kg}$. When examined at the age of 13 years (Fig. 2), she presented with a disproportionate short stature, short arms and a very short neck. Her face was round with midfacial hypoplasia, prominent eyes, downslanting palpebral fissures, blue sclerae, a long philtrum, a bifid uvula and a high-arched palate. She displayed generalized joint hypermobility, bilateral radial head dislocation, genua valga, pes planus and hallux valgus. Her fingers had a tapered aspect with spatulate distal phalanges. Motor development was mildly delayed but intelligence was normal. Bone mineral density at the age of 18 years was low with a Z-score of $-1,8$ at L1-L4, without fractures. Radiographic imaging showed radial head dislocation, subluxation of the knees, a short femoral neck and irregular tarsal bones. Cardiac investigations were not performed.

\section{Molecular and structural analyses}

Whole exome sequencing in patient 1 identified a homozygous c.667G > A, p.(Gly223Ser) missense variant in B3GAT3. This mutation has been reported previously in 7 patients [37] and is absent in the GnomAD database. This variant is predicted to be 'probably damaging' (Polyphen-2) and 'deleterious' (SIFT), but is regarded as a polymorphism by MutationTaster. Whole exome sequencing in patient 2 revealed a novel homozygous missense variant c.416C $>\mathrm{T}$, p.(Thr139Met) in B3GAT3. This variant is found in only 1 of 249,250 alleles (allele frequency 4.012e-6) in the GnomAD database. This residue is highly conserved as shown in Fig. 3 and predicted as pathogenic by Polyphen-2 and MutationTaster.

\section{Structural modelling of missense variants}

To date, 7 B3GAT3 mutations have been reported, including our newly found variant. There are 6 missense mutations: c.245C > T, p.(Pro82Leu); c.416C > T, p.(Thr139Met); c.419C $>$ T, p.(Pro140Leu); c.667G $>$ A, p.(Gly223Ser); c.671 T > A, p.(Leu224Gln) and c.830G > A, p.(Arg277Gln) . All occur in homozygous state, except for the c.671 T > A, p.(Leu224Gln) variant, which was found in compound heterozygosity with a null-variant (c.1A > G), p.(Met1?) [32, 33, 35-39]. Recently, a heterozygeous splice-site variant c. $888+262 \mathrm{~T}>\mathrm{G}$ was found in one patient [34]. GlcAT-I, located at the Golgi apparatus membrane, consists of multiple domains: a small cytoplasmic domain (res. 1-7), a transmembrane domain (res. 8-25), a proline-rich stem region (res. 26-74) and a catalytic domain consisting of an UDP-GlcUA (uridine diphosphate - ( $\beta$-D-)glucuronic acid) donor substrate binding subdomain (res. 75-197) and an acceptor substrate binding subdomain (res. 198-308) [40]. All 5 missense variants are located within the catalytic domain of the protein. We performed structural modelling of these missense variants on the protein structure of GlcAT-I (Fig. 3).

\section{Mutations in the donor substrate binding subdomain}

The in silico model of the p.(Pro82Leu) variant showed a clear overlap in the Van Der Waals forces, indicating possible unfavourable interactions because of a disturbance in the balance of the Van Der Waals forces in this variant. The alteration of threonine to methionine residue in the p.(Thr139Met) variant, identified in our 
Table 1 Summary of clinical features in all reported patients with biallelic B3GAT3 mutations

\begin{tabular}{|c|c|c|c|c|c|c|c|c|c|}
\hline & \multicolumn{6}{|c|}{ Previously reported patients } & \multicolumn{2}{|c|}{ New patients } & \multirow[t]{2}{*}{ Total $^{c}$} \\
\hline & c.830G > A $[32,38]$ & $\begin{array}{l}\text { c. } 419 C>T \\
{[35]}\end{array}$ & $\begin{array}{l}\text { c.1A }>\mathrm{G}+\mathrm{c} .671 \mathrm{~T}>\mathrm{A} \\
{[36]}\end{array}$ & $\begin{array}{l}\text { c.245C }>\mathrm{T} \\
{[33]}\end{array}$ & $\begin{array}{l}\mathrm{c} .667 \mathrm{G}>\mathrm{A} \\
{[37,39]}\end{array}$ & $\begin{array}{l}\text { Het. c.888 + } \\
262 T>\text { G [34] }\end{array}$ & $\begin{array}{l}1 . \\
\text { C. } 667 \mathrm{G}> \\
\text { A }\end{array}$ & $\begin{array}{l}2 . \\
\text { C.416C> } \\
T\end{array}$ & \\
\hline $\mathrm{N}^{\circ}$ of patients & 6 & 8 & 1 & 1 & 7 & 1 & 1 & 1 & 26 \\
\hline Short stature & $6 / 6(>p 3)$ & $8 / 8(>\mathrm{P} 3)$ & $0 / 1$ & $1 / 1$ & $\begin{array}{l}1 / 4 \text { (NR in } \\
3)\end{array}$ & $1 / 1$ & Yes & Yes & $\begin{array}{l}19 / 23 \\
(83 \%)\end{array}$ \\
\hline $\begin{array}{l}\text { Skeletal } \\
\text { dysplasia }^{a}\end{array}$ & $6 / 6$ & $8 / 8$ & $1 / 1$ & $1 / 1$ & $7 / 7$ & $1 / 1$ & Yes & Yes & $\begin{array}{l}26 / 26 \\
(100 \%)\end{array}$ \\
\hline $\begin{array}{l}\text { Joint } \\
\text { hypermobility }\end{array}$ & $6 / 6$ & $0 / 8$ & $1 / 1$ & NR & $\begin{array}{l}0 / 1 \text { (NR in } \\
6)\end{array}$ & $1 / 1$ & Yes & Yes & $\begin{array}{l}10 / 19 \\
(53 \%)\end{array}$ \\
\hline $\begin{array}{l}\text { Joint } \\
\text { dislocations }\end{array}$ & $\begin{array}{l}\text { 6/6 (elbow, } \\
\text { shoulders, } \\
\text { radioulnar, hip) }\end{array}$ & $\begin{array}{l}8 / 8 \text { (elbow, } \\
\text { shoulder) }\end{array}$ & 1/1 (left hip) & NR & $3 / 7$ & $0 / 1$ & No & Yes & $\begin{array}{l}18 / 25 \\
(72 \%)\end{array}$ \\
\hline Fractures & NR & NR & $\begin{array}{l}\text { 1/1 (multiple } \\
\text { fractures of femur } \\
\text { and tibia) }\end{array}$ & $1 / 1$ & $5 / 6$ & $0 / 1$ & Yes & No & $\begin{array}{l}8 / 12 \\
(67 \%)\end{array}$ \\
\hline $\begin{array}{l}\text { Joint } \\
\text { contractures }\end{array}$ & $5 / 6$ (elbow) & 4/8 (elbow) & NR & NR & $7 / 7$ & $N R$ & Yes & No & $\begin{array}{l}11 / 16 \\
(69 \%)\end{array}$ \\
\hline $\begin{array}{l}\text { Facial } \\
\text { dysmorphology }\end{array}$ & $6 / 6$ & $8 / 8$ & $1 / 1$ & NR & $6 / 7$ & $1 / 1$ & Yes & Yes & $\begin{array}{l}25 / 25 \\
(100 \%)\end{array}$ \\
\hline $\begin{array}{l}\text { Cardiovascular } \\
\text { involvement }\end{array}$ & $\begin{array}{l}6 / 6 \text { (bicuspid } \\
\text { aortic valve, aortic } \\
\text { root dilatation, } \\
\text { mitral valve } \\
\text { prolapse, ASD, } \\
\text { VSD) }\end{array}$ & $\begin{array}{l}0 / 3(\mathrm{Not} \\
\text { investigated } \\
\text { in 5) }\end{array}$ & $\begin{array}{l}\text { 1/1 (PFO, bicuspid } \\
\text { aortic valve, diltation } \\
\text { of aortic root and } \\
\text { ascendig aorta) }\end{array}$ & NR & $\begin{array}{l}\text { 4/7 (ASD, } \\
\text { VSD, patent } \\
\text { ductus } \\
\text { arteriosus) }\end{array}$ & $\begin{array}{l}1 / 1 \text { (VSD, } \\
\text { pulmonary } \\
\text { stenosis) }\end{array}$ & No & $\mathrm{Nl}$ & $\begin{array}{l}12 / 20 \\
(60 \%)\end{array}$ \\
\hline $\begin{array}{l}\text { Intellectual } \\
\text { disability }\end{array}$ & $1 / 6$ & $0 / 5$ & $1 / 1$ & NR & 1 (NR in 6) & $N R$ & - & No & $\begin{array}{l}2 / 14 \\
(14 \%)\end{array}$ \\
\hline $\begin{array}{l}\text { Ocular } \\
\text { involvement }\end{array}$ & $\begin{array}{l}\text { 1/1 (hyperopia, } \\
\text { esotropia, } \\
\text { amblyopia) }\end{array}$ & $N R$ & $\begin{array}{l}\text { 1/1 (hyperopia, } \\
\text { astigmatism, } \\
\text { amblyopia and left } \\
\text { ptosis) }\end{array}$ & NR & $\begin{array}{l}1 \text { with } \\
\text { bilateral } \\
\text { glaucoma } \\
\text { (NR in 6) }\end{array}$ & $N R$ & $\begin{array}{l}\text { Yes } \\
\text { (Corneal } \\
\text { clouding) }\end{array}$ & No & 4 \\
\hline Blue sclerae & $N R$ & $N R$ & $1 / 1$ & NR & 1 (NR in 6) & NR & Yes & Yes & 4 \\
\hline $\begin{array}{l}\text { Spatulate } \\
\text { phalanges }\end{array}$ & $6 / 6$ & $8 / 8$ & $N R$ & $N R$ & 1 (NR in 6) & $N R$ & Yes & Yes & $\begin{array}{l}16 / 17 \\
(94 \%)\end{array}$ \\
\hline $\begin{array}{l}\text { Hyperextensible } \\
\text { skin }\end{array}$ & $0 / 1$ (NR in 5) & NR & $1 / 1$ & $N R$ & $0 / 7$ & $N R$ & No & No & 1 \\
\hline Cutis laxa & $N R$ & $N R$ & $N R$ & $1 / 1$ & $N R$ & $N R$ & Yes & No & 2 \\
\hline Hearing loss & $N R$ & NR & NR & NR & $\begin{array}{l}1 \text { with } \\
\text { bilateral } \\
\text { conductive } \\
\text { (NR in 6) }\end{array}$ & $\begin{array}{l}1 / 1 \\
\text { (sensorineural) }\end{array}$ & $\mathrm{NI}$ & No & 2 \\
\hline $\begin{array}{l}\text { Aditional } \\
\text { features }\end{array}$ & $\begin{array}{l}\text { Excessive wrinkling } \\
\text { of the skin in } 1\end{array}$ & & $\begin{array}{l}\text { Restrictive lung } \\
\text { disease due to } \\
\text { scoliosis }+ \\
\text { macrocepahly + } \\
\text { hypoglycemia + } \\
\text { hypothyroidism }\end{array}$ & $\begin{array}{l}\text { Multiple } \\
\text { bony } \\
\text { chondroma }\end{array}$ & $\begin{array}{l}6 \text { patients } \\
\text { died before } \\
\text { the age of } \\
1 \text { year }\end{array}$ & $\begin{array}{l}\text { Posterior } \\
\text { cloaca }+ \\
\text { ketotic } \\
\text { hypoglycemia } \\
+\mathrm{GH} \\
\text { deficiency }\end{array}$ & $\begin{array}{l}\text { Died } \\
\text { before } \\
\text { the age } \\
\text { of } 1 \text { year }\end{array}$ & & \\
\hline
\end{tabular}

NR Not Reported, NI Not Investigated

a Skeletal dysplasia including shortening and bowing of long bones, severe (kypho)scoliosis, foot deformity and radioulnar synostosis

${ }^{b}$ Facial dysmorhpology including abnormalities in cephalic index (brachycephaly and dolichocephaly), frontal bossing, hypertolerism, prominent eyes, downslanting palpebral fissures, midfacial hypoplasia, depressed nasal bridges, microstomia and short neck

c Total based on the reported frequency 

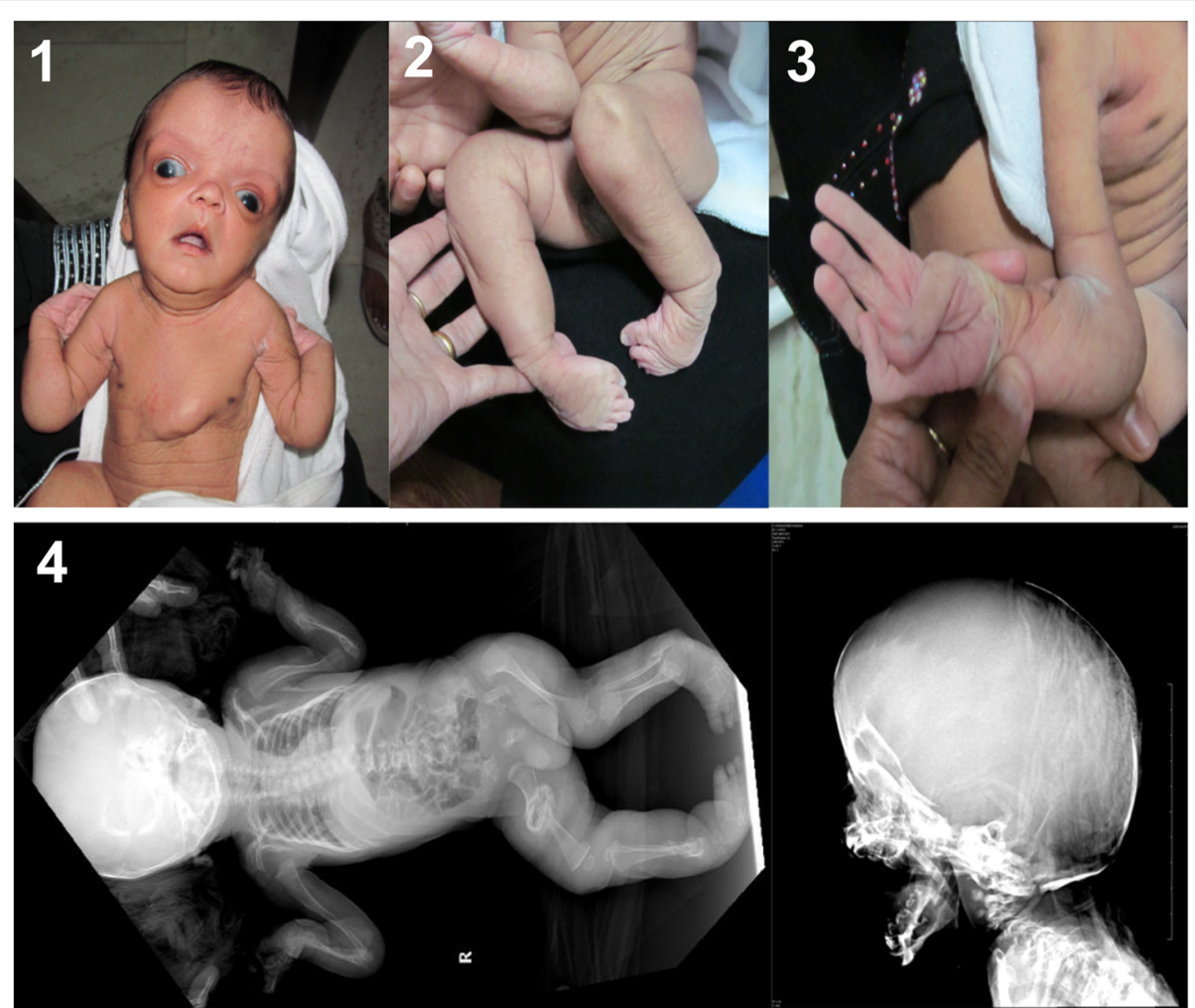

Fig. 1 Patient 1 with severe dysmorphic features. There is bulging of the thoracic cage, hypertolerism, downslanting palpebral fissures, lagophtalmos of the lower eye lids, blue sclerae, a pug nose, low-set and dysplastic ears, corneal clouding [1], generalized cutis laxa [1-3], long fingers with campylodactyly and adducted thumbs, broad tips of fingers and toes and bilateral club feet [2, 3]. Perinatal radiography shows osteopenia, multiple fractures, large joint contractures and Wormian bones in the occipital region [4]

patient 2, was predicted to induce 8 new clashes (close contacts between atoms), disrupt $3 \mathrm{H}$-bonds and a change of surface hydrophobicity was found. The modelling of the p.(Pro140Leu) variant showed an alteration of the surface hydrophobicity.

\section{Mutations in the acceptor substrate binding subdomain} The substitution of a glycine by a serine in the p.(Gly223Ser) variant was predicted to cause a new Hbond and 6 clashes. Additionally, a report from Gulberti et al. [41] showed that substitution of p.Gly223 with a bigger alanine residue strongly impaired the enzyme function, suggesting an essential role of this residue for substrate specificity. The p.(Leu224Gln) variant was predicted to cause 4 clashes, and a new overlap between Van Der Waals forces was seen. Due to the localization of the last two variants close to the other protein sequence of the homodimer, they may interfere in the dimerization process. In the p.(Arg277Gln), two new clashes were predicted. In a previously reported mutagenesis experiment, the p.Arg277 residue was confirmed to be essential for the enzymic activity of GlcAT-I [42].

Overall, more alterations were predicted with the variants located in the substrate acceptor subdomain. Also, more literature evidence is available on the importance of the affected residues in this subdomain for enzymatic activity of GlcAT-I (Table 2).

\section{Discussion}

Glucuronyltransferase I, encoded by B3GAT3, catalyzes the addition of the ultimate sugar residue of the tetrasaccharide linker region between the core protein and the glycosaminoglycan side chains of PG. Homozygous lossof-function of glucuronyltransferase I causes an heterogenic multisystemic disorder. To date, 23 patients from 10 families with biallelic B3GAT3 mutations and one patient with a heterozygeous splice-site mutation in B3GAT3 have been reported. Consistent findings include a skeletal dysplasia with disproprionate short stature, kyphosis, scoliosis and deformity of the long bones, spatulate distal phalanges, and facial dysmorphology. Joint hypermobility, joint dislocations/contractures, bone fragility and congenital heart defects are variably present. Other, more infrequent features are ocular problems, intellectual disablilty and skin abnormalities. The two new unrelated individuals we present here showed a clear phenotypic overlap with the previously reported patients. Patient 1 , harbouring the p.(Gly223Ser) variant, presented with a severe phenotype 

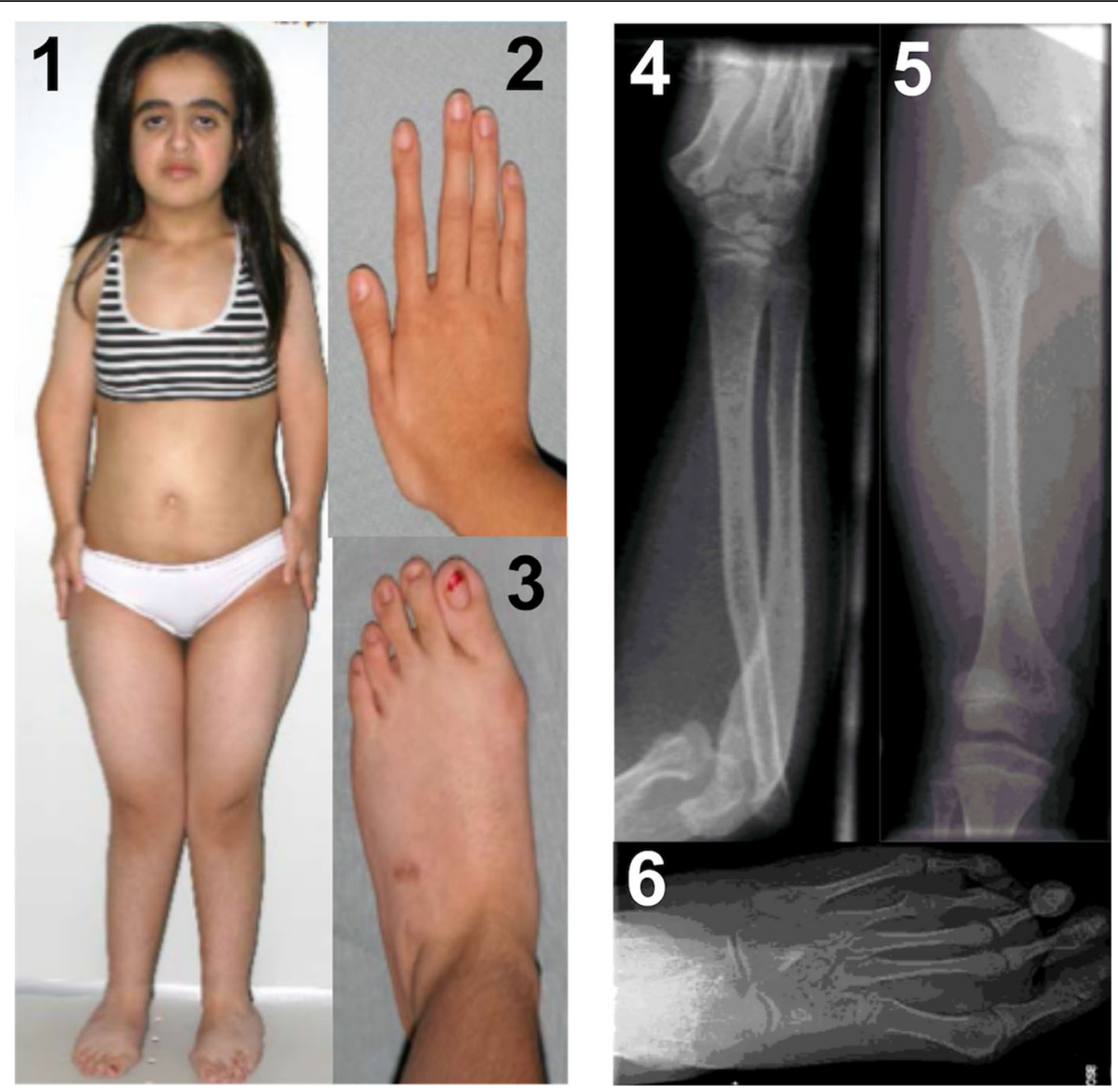

Fig. 2 Patient 2 at age 13 yrs. with a disproprionate short stature, genu valgum, a round flat face with midfacial hypoplasia, blue sclerae, downslanting palpebral fissures and prominent eyes [1]. She has long fingers with spatulate distal phalanges and pes planus with hallux valgus $[2,3]$. Radiography shows radial head dislocation, short femoral neck, subluxation of the knee joint and irregular tarsal bones [4-6]

including contractures of both large and small joints, multiple fractures, an asymetric thoracic cage, severe dysmorphic facial features, cutis laxa and corneal clouding, the latter being a unique finding. He died at the age of 2.5 months. Patient 2, in which a novel p.(Thr139Met) variant was found, displayed a milder phenotype with short stature, facial dysmorphic features, joint hypermobility and spatulate distal phalanges.

To date only 7 B3GAT3 mutations have been identified. Although the total number of patients with B3GAT3 mutations is still very small, some genotype-phenotype patterns start to emerge. All patients harbouring the c.667G > A, p.(Gly223Ser) substitution, including our patient 1 , have a strikingly severe phenotype with a high mortality soon after birth. Also the phenotype of the patients harbouring the c.830G > A, p.(Arg277Gln) variant and the compound heterozygous mutation c. $[1 \mathrm{~A}>\mathrm{G}]$; [671 T > A], p. [(Met1?)]; [(Leu224Gln)] seem to be at the severe end of the spectrum. In contrast, our patient 2 with c.416C > T, p.(Thr139Met) displays a milder phenotype, as do the affected members of the family harbouring
c.419C > T, p.(Pro140Leu) mutations and the individual with the heterozygeous splice site mutation c. $888+262$ $\mathrm{T}>\mathrm{G}$. The clinical data available of the patient with the c. $245 \mathrm{c}>$ T, p.(Pro82Leu) variant is too limited to draw any conclusions about the severity of the phenotype. Data on functional consequences of these mutations was only reported on 3 of the 7 reported mutations. Compared with wild type, the enzyme activity of the p.(Leu224Gln) and p.(Arg277Gln) variants was reduced to $3-5 \%$ and in the p.(Pro140Leu) variant, possibly associated with a milder phenotype, a residual enzyme activity to $10 \%$ was detected. In the p.(Leu224Gln) and p.(Arg277Gln) variants, a significant reduction of GlcAT-I protein levels was noted in patient fibroblasts, with normal levels of mRNA. No significant differences were found in protein levels when using a recombinant cell system in which vectors of the p.(Pro140Leu) and the p.(Arg277Gln) variants were transfected. This suggests a decrease in activity of the mutant protein affecting the stability of the protein rather than a reduced production. In all 3 variants the amount of CS and HS chains was reduced, indicating a disruption of the 


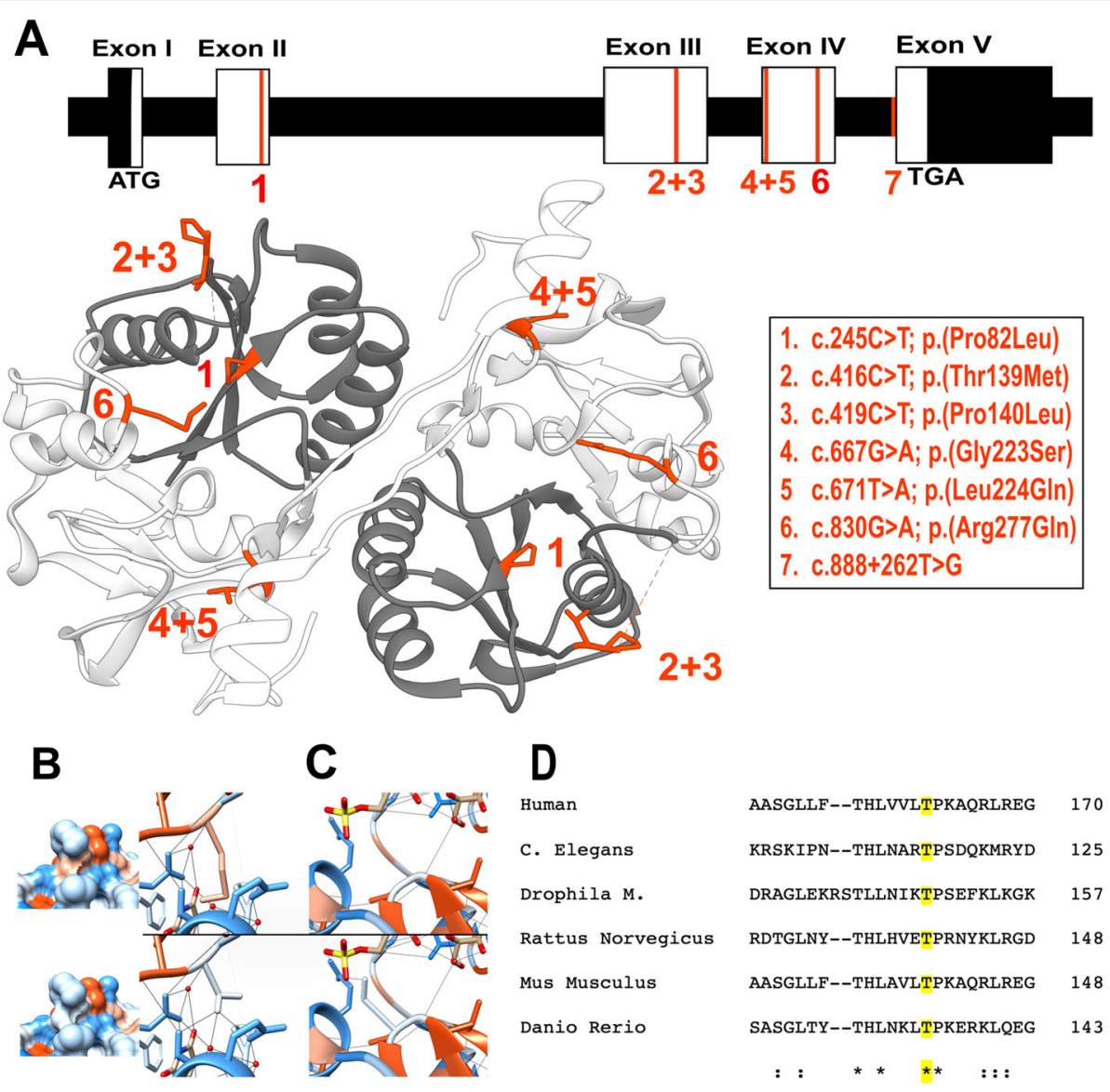

Fig. 3 a Overview of all the known pathogenic mutations on a schematic representation of the CDNA and gDNA transcript of B3GAT3 on top and a representation of all missense mutations on an in silico model of GlcAT-I in which the substrate donor is colored in dark grey and the substrate acceptor subdomain is colored light grey. All mutations are highlighted in red. b-c In silico modelling. Hydrophilic residues are blue, hydrophobic residues are red. $\mathbf{b}$ p.Thr139 (top row) and the p.(Thr139Met) variant (below) with hydrophobicity surface rendering showing a change in the missense variant. The right column shows the disruption of $3 \mathrm{H}$-bonds in the missense variant. c The p.Gly223 residue (on top) and the p.(Gly223Ser) variant (below) showing the formation of a new $\mathrm{H}$-bond. $\mathbf{d}$ Clustal Omega protein sequence aligment showing that the protein sequence of GlcAT-I is (largely) conserved across vertebrates and invertebrates. Asterisks indicate a single, fully conserved residue, colons indicate strong similar properties (>0.5 on the Gonnet PAM 250 matrix), and periods indicate weak similar properties ( $<0.5$ in the Gonnet PAM 250 matrix). The sequence alignment shows the high conservation of the Thr residue on position 139 of the sequence (marked in yellow)

Table 2 Results of the in silico modelling of all missense variants in B3GAT3

\begin{tabular}{|c|c|c|c|c|c|c|c|c|}
\hline $\begin{array}{l}\text { Missense } \\
\text { variant }\end{array}$ & Location & $\begin{array}{l}\text { Change in } \mathrm{H} \text { - } \\
\text { bonds }\end{array}$ & $\begin{array}{l}\text { New } \\
\text { clashes }\end{array}$ & $\begin{array}{l}\text { Change in surface } \\
\text { hydrophobicity }\end{array}$ & $\begin{array}{l}\text { Possible effect on } \\
\text { dimerisation }\end{array}$ & $\begin{array}{l}\text { Overlap in Van Der } \\
\text { Waals forces }\end{array}$ & $\begin{array}{l}\text { Literature } \\
\text { evidence }\end{array}$ & Total \\
\hline p.(Pro82Leu) & $\begin{array}{l}\text { Substrate donor } \\
\text { subdomain }\end{array}$ & I & I & / & I & + & I & 1 \\
\hline p.(Thr139Met) & $\begin{array}{l}\text { Substrate donor } \\
\text { subdomain }\end{array}$ & $+(3)$ & $+(8)$ & + & / & / & / & 3 \\
\hline p.(Pro140Leu) & $\begin{array}{l}\text { Substrate donor } \\
\text { subdomain }\end{array}$ & / & / & + & / & / & / & 1 \\
\hline p.(Gly223Ser) & $\begin{array}{l}\text { Substrate acceptor } \\
\text { subdomain }\end{array}$ & $+(1)$ & $+(6)$ & / & + & / & + & 4 \\
\hline p.(Leu224GIn) & $\begin{array}{l}\text { Substrate acceptor } \\
\text { subdomain }\end{array}$ & / & $+(4)$ & / & + & + & / & 3 \\
\hline p.(Arg277Gln) & $\begin{array}{l}\text { Substrate acceptor } \\
\text { subdomain }\end{array}$ & / & $+(2)$ & / & / & / & + & 2 \\
\hline
\end{tabular}

/: no alteration was predicted 
effective GAG synthesis [32, 35, 36]. In order to gain insight in the molecular consequences of the reported missense mutations on protein structure, we performed in silico modelling. Strikingly, all missense variants associated with a more severe phenotype are located in the substrate acceptor subdomain of the catalytic domain of GlcAT-I. Overall, more changes in H-bonds and more unfavourable contacs or overlap in Van Der Waals forces were found in the variants located in the substrate acceptor subdomain.

Biallelic mutations have been identified in all five genes coding for the enzymes involved in the synthesis of the tetrasaccharide linker region (Table 3). Each of these linkeropathies is characterized by specific phenotypical patterns, although there is an important overlap. All are characterized by a disproportionate short stature with short limbs, (kypho)scoliosis and an asymmetric/ small thorax. Another persistent finding is the presence of facial dysmorphology with a wide spectrum of findings including wide forehead, downslanting palpebral fissures, large eyes, blue sclerae, depressed nasal bridge and midfacial hypoplasia. Excessive joint laxity is present in all disorders, except in XYLT2 mutations. Joint contractures are only reported in B3GALT6 and B3GAT3 mutations, whereas multiple fractures due to bone fragility are commonly found in patients harbouring B3GALT6 and $X Y L T 2$ mutations and to a lesser extent in mutations in B3GAT3, B3GALT7 and B4GALT7. Cardiac defects, including septal defects and valve defects, are associated with mutations in XYLT2, B3GAT3 and, to a lesser extend, B3GALT6. Ocular involvement is present in most reported patients with $X Y L T 2$ (cataract and retinal detachment) and B4GALT7 mutations and is a rare and variable finding in B3GAT3 mutations. Hearing loss is associated with mutations in XYLT2 while this is uncommon in the other linkeropathies. Hyperextensible skin is associated with mutations in B4GALT7 and B3GALT6 and, as mentioned above, some patients with B3GAT3 mutations have skin involvement. Intellectual disability is reported in all linkeropathies with a variable frequency. Mild to moderate intellectual disability is present in most individuals with mutations in B4GALT7 and all patients with mutations in XYLT1 suffer from a degree of intellectual disability. A recent report by La Croix et al. described the presence of biallelic pathogenic variants in XYLT1 (including a trinucleotide repeat expansion associated with hypermetylation) in patients diagnosed with Baratela-Scott syndrome (BSS) which is characterized by short stature, facial dysmorphology and intellectual disability [43]. They stated that further detailed phenotyping is necessary to determine whether BSS and Desbuquois dysplasia type II can be distinguished by the presence of intellectual disability or not. Based on our literature overview, an important overlap in clinical features exists with presence of intellectual disability in both.

\section{Conclusion}

In summary, loss-of-function mutations in B3GAT3 are associated with a complex connective tissue phenotype characterized by disproportionate short stature, skeletal dysplasia, facial dysmorphism, spatulate distal phalanges and -to a lesser extent- joint contractures, joint hypermobility with dislocations, cardiac defects and bone fragility. Based on the limited number of reported patients, some genotype-phenotype correlations start to emerge. However, pheno- and genotyping of additional patients with mutations in linkeropathy-associated genes, and study of the spatiotemporal effects of the specific mutations on enzyme activities and GAG synthesis is needed in order to better understand the disease mechanisms and phenotypic outcomes of these linkeropathies.

Table 3 comparison between the linkeropathies

\begin{tabular}{llllll}
\hline & XYLT1 [11-16] & XYLT2 [17-22] & B4GALT7 ${ }^{[23-28]}$ & B3GALT6 [10, 30, 31] & B3GAT3 [32-39] \\
\hline Short stature & $100 \%(15 / 15)$ & $53 \%(9 / 17)$ & $100 \%(8 / 8)$ & $100 \%(27 / 27)$ & $83 \%(19 / 23)$ \\
Skeletal dysplasia $^{b}$ & $100 \%(15 / 15)$ & $94 \%(16 / 17)$ & $100 \%(8 / 8)$ & $100 \%(27 / 27)$ & $100 \%(26 / 26)$ \\
Joint hypermobility & $40 \%(6 / 15)$ & NR & $100 \%(8 / 8)$ & $88 \%(22 / 25)$ & $53 \%(10 / 19)$ \\
Bone fragility & $7 \%(1 / 15)$ & $94 \%(16 / 17)$ & $62 \%(5 / 8)$ & $48 \%(13 / 27)$ & $67 \%(8 / 12)$ \\
Joint contractures & NR & NR & $37 \%(3 / 8)$ & $59 \%(16 / 27)$ & $69 \%(11 / 16)$ \\
Facial dysmorphology & $100 \%(15 / 15)$ & $65 \%(11 / 17)$ & $87 \%(7 / 8)$ & $100 \%(25 / 25)$ & $100 \%(25 / 25)$ \\
Hyperextensible skin/ cutis laxa & NR & NR & $87 \%(7 / 8)$ & $68 \%(17 / 25)$ & $12 \%($ reported in 3) \\
Cardiovascular involvement & $7 \%(1 / 15)$ & $35 \%(6 / 17)$ & NR & $16 \%(4 / 25)$ & $60 \%(12 / 20)$ \\
Intellectual disability & $100 \%($ Present in all older patients) & $35 \%(6 / 17)$ & $75 \%(6 / 8)$ & $20 \%(5 / 25)$ & $14 \%(2 / 14)$ \\
Ocular involvement & NR & $88 \%(15 / 17)$ & $62 \%(5 / 8)$ & NR & $15 \%($ reported in 4) \\
Hearing loss & $7 \%(1 / 15)$ & $53 \%(9 / 17)$ & $25 \%(2 / 8)$ & NR & $8 \%($ reported in 2) \\
\hline
\end{tabular}

${ }^{a}$ With exclusion of the Larsen of Reunion Island syndrome cohort from Crathault et al. [23]

b Skeletal dysplasia including shortening and deformity of long bones, (kypho)scoliosis, small thoracic cage, radioulnar synostosis, deformity of the feet

c Facial dysmorhpology including wide forehead, downslanting palpebral fissures, large eyes, blue sclerae, depressed nasal bridge and midfacial hypoplasia 


\section{Methods}

\section{Case reports}

Both patients were referred to a clinical geneticist because of the suspicion of a complex heritable connective tissue disorder. DNA samples were obtained from both patients and their parents. Informed consent was obtained from the patients and parents participating in this study. They consented to the publication of clinical photographs.

\section{Molecular analyses}

Whole-exome sequencing was performed for patient 1 and 2 and their parents using HiSeq 3000 (Illumina) and SOLID 5500 (ThermoFisher), respectively. Reads were mapped and variants were called and annotated with the BCbio pipeline. Variants found in patient 1 were analyzed using our in-house developed analysis platform Seqplorer. The identified variants were confirmed with bidirectional sequencing. Nucleotide numbering reflects cDNA numbering, with +1 corresponding to the $\mathrm{A}$ of the ATG translation initiation codon in the reference sequence (NM_0012200). Amino acid residues are numbered from the first methionine residue of the reference sequence (NP_001275650). Pathogenicity of the variants was evaluated using PolyPhen-2 (http://genetics.bwh. harvard.edu/pph2), MutationTaster (http://www.mutationtaster.org) and SIFT (http://sift.bii.a-star.edu.sg) in patient 1 and with PolyPhen-2 and MutationTaster in patient 2. Occurrence was assessed using the GnomAD database (http://gnomad.broadinstitute.org) [44].

\section{Structural modeling}

Protein structure of GlcAT-I was obtained from the RCSB Protein DataBank (https://www.rcsb.org). The protein structure previously reported by Tone et al. (3CU0) was used as reference [9]. This model contains GlcAT-I in a complex with UDP, $\mathrm{Mn}^{2+}$, and Galß1-3Gal(6-O-sulfate) $\beta 1-4 \mathrm{Xyl}(2-\mathrm{O}$-phosphate) $\beta 1-\mathrm{O}-\mathrm{Ser}$. Visualisation of the protein structure was performed using UCSF Chimera (candidate version 1.13.1, build 41,911) [45]. Using the rotamers function, all missense variants were modelled into the protein structure. The 'Find H-Bond function' was used to identify potential hydrogen bonds based on the distance between atoms and possible unfavorable interactions were atoms are too close to each other were identified with visualization of the Van Der Waals forces and the 'Find Clashes/Contacts function'.

\section{Abbreviations}

EDS: Ehlers-Danlos Syndrome; GAG: Glycosaminoglycans; GlcAT-

I: Glucuronosyltransferase I; PG: proteoglycans

\section{Acknowledgements}

We thank the patients and their families for their contribution to the study. DS and FM are a postdoctoral researcher and a clinical research fellow, respectively, of the Research Foundation Flanders (FWO), Belgium.

\begin{abstract}
Authors' contributions
Contributed to the writing of the manuscript: MC, TVD, DS, FM. Performed genetic investigations: SS, FL. Contributed to the clinical data of the patients: ES, SN. Performed/ contributed to the structural modelling: MC, TVD, BG. All authors reviewed and approved the final manuscript.
\end{abstract}

\section{Funding}

This work was supported by a Methusalem Grant from Ghent University to Anne De Paepe (BOFMET2015000401).

\section{Availability of data and materials}

The data that support the findings of this study are available on request from the corresponding author on reasonable request.

Ethics approval and consent to participate

Informed consent was obtained from the patients and parents participating in this study.

\section{Consent for publication}

Consent was obtainend from the parents of the patients for punblication of clinical data and photographic images.

\section{Competing interests}

The authors declare that they have no competing interests.

\section{Author details}

${ }^{1}$ Center for Medical Genetics, Ghent University and Ghent University Hospital, 0K5, Corneel Heymanslaan 10, B-9000 Ghent, Belgium. ²Department of Pediatrics, Medical University of Innsbruck, Innsbruck, Austria. ${ }^{3}$ Institute of Medical Genetics, Vienna, Austria. ${ }^{4}$ Department of Pediatric Genetics, Amrita Institute of Medical Sciences \& Research Centre, Kerala, India.

Received: 23 January 2019 Accepted: 4 June 2019

Published online: 13 June 2019

\section{References}

1. Bishop JR, Schuksz M, Esko JD. Heparan sulphate proteoglycans fine-tune mammalian physiology. Nature. 2007:446(7139):1030-7.

2. Couchman JR, Pataki CA. An introduction to proteoglycans and their localization. J Histochem Cytochem. 2012;60(12):885-97.

3. Häcker U, Nybakken K, Perrimon N. Heparan sulphate proteoglycans: the sweet side of development. Nat Rev Mol Cell Biol. 2005;6(7):530-41.

4. Okajima T, Yoshida K, Kondo T, Furukawa K. Human homolog of Caenorhabditis elegans sqv-3 gene is galactosyltransferase I involved in the biosynthesis of the glycosaminoglycan-protein linkage region of proteoglycans. J Biol Chem. 1999;274(33):22915-8.

5. Kitagawa H, Tone Y, Tamura J-i, Neumann KW, Ogawa T, Oka S, et al. Molecular cloning and expression of glucuronyltransferase I involved in the biosynthesis of the glycosaminoglycan-protein linkage region of proteoglycans. J Biol Chem. 1998;273(12):6615-8.

6. Götting C, Kuhn J, Zahn R, Brinkmann T, Kleesiek K. Molecular cloning and expression of human UDP-D-xylose: proteoglycan core protein $\beta-D-$ xylosyltransferase and its first isoform XT-II. J Mol Biol. 2000;304(4):517-28.

7. Bai X, Zhou D, Brown JR, Crawford BE, Hennet T, Esko JD. Biosynthesis of the linkage region of Glycosaminoglycans cloning and activity of galactosyltransferase ii, the sixth member of the $\beta 1$, 3-galactosyltransferase family (B3GalT6). J Biol Chem. 2001;276(51):48189-95.

8. Almeida R, Levery SB, Mandel U, Kresse H, Schwientek T, Bennett EP, et al. Cloning and expression of a proteoglycan UDP-galactose: $\beta$-xylose $\beta 1,4-$ galactosyltransferase IA seventh member of the human $\beta 4$ galactosyltransferase gene family. J Biol Chem. 1999;274(37):26165-71.

9. Tone $Y$, Pedersen LC, Yamamoto T, Izumikawa T, Kitagawa H, Nishihara J, et al. 2-o-phosphorylation of xylose and 6-o-sulfation of galactose in the protein linkage region of glycosaminoglycans influence the glucuronyltransferase-I activity involved in the linkage region synthesis. J Biol Chem. 2008;283(24):16801-7.

10. Nakajima M, Mizumoto S, Miyake N, Kogawa R, lida A, Ito H, et al. Mutations in B3GALT6, which encodes a glycosaminoglycan linker region enzyme, cause a spectrum of skeletal and connective tissue disorders. Am J Hum Genet. 2013;92(6):927-34. 
11. Bui C, Huber C, Tuysuz B, Alanay Y, Bole-Feysot C, Leroy JG, et al. XYLT1 mutations in Desbuquois dysplasia type 2. Am J Hum Genet. 2014;94(3):405-14.

12. Guo L, Elcioglu NH, lida A, Demirkol YK, Aras S, Matsumoto N, et al. Novel and recurrent XYLT1 mutations in two Turkish families with Desbuquois dysplasia, type 2. J Hum Genet. 2017;62(3):447-51.

13. Jamsheer A, Olech EM, Kozlowski K, Niedziela M, Sowinska-Seidler A, ObaraMoszynska $M$, et al. Exome sequencing reveals two novel compound heterozygous XYLT1 mutations in a polish patient with Desbuquois dysplasia type 2 and growth hormone deficiency. J Hum Genet. 2016;61(7):577-83.

14. Schreml J, Durmaz B, Cogulu O, Keupp K, Beleggia F, Pohl E, et al. The missing "link": an autosomal recessive short stature syndrome caused by a hypofunctional XYLT1 mutation. Hum Genet. 2014;133(1):29-39.

15. Silveira C, Leal GF, Cavalcanti DP. Desbuquois dysplasia type II in a patient with a homozygous mutation in XYLT1 and new unusual findings. Am J Med Genet A. 2016:170(11):3043-7.

16. van Koningsbruggen $S$, Knoester $H$, Bakx R, Mook O, Knegt L, Cobben JM. Complete and partial XYLT1 deletion in a patient with neonatal short limb skeletal dysplasia. Am J Med Genet A. 2016;170a(2):510-4.

17. Guleray N, Simsek Kiper PO, Utine GE, Boduroglu K, Alikasifoglu M. Intrafamilial variability of XYLT2-related spondyloocular syndrome. Eur J Med Genet; 2018. Available from: https://www.sciencedirect.com/science/article/ pii/S1769721218306116. [Epub ahead of print]

18. Munns CF, Fahiminiya S, Poudel N, Munteanu MC, Majewski J, Sillence DO, et al. Homozygosity for frameshift mutations in XYLT2 result in a spondyloocular syndrome with bone fragility, cataracts, and hearing defects. Am J Hum Genet. 2015;96(6):971-8.

19. Schmidt H, Rudolph G, Hergersberg M, Schneider K, Moradi S, Meitinger T. Retinal detachment and cataract, facial dysmorphism, generalized osteoporosis, immobile spine and platyspondyly in a consanguinous kindred--a possible new syndrome. Clin Genet. 2001;59(2):99-105.

20. Taylan F, Costantini A, Coles N, Pekkinen M, Heon E, Siklar Z, et al. Spondyloocular syndrome: novel mutations in XYLT2 gene and Expansion of the phenotypic Spectrum. J Bone Miner Res. 2016;31(8):1577-85.

21. Taylan F, Yavas Abali Z, Jantti N, Gunes N, Darendeliler F, Bas F, et al. Two novel mutations in XYLT2 cause spondyloocular syndrome. Am J Med Genet A. 2017;173(12):3195-200.

22. Umair M, Eckstein G, Rudolph G, Strom T, Graf E, Hendig D, et al. Homozygous XYLT2 variants as a cause of spondyloocular syndrome. Clin Genet. 2018;93(4):913-8.

23. Arunrut T, Sabbadini M, Jain M, Machol K, Scaglia F, Slavotinek A. Corneal clouding, cataract, and colobomas with a novel missense mutation in B4GALT7-a review of eye anomalies in the linkeropathy syndromes. Am J Med Genet A. 2016;170(10):2711-8.

24. Faiyaz-Ul-Haque M, Zaidi SH, Al-Ali M, Al-Mureikhi MS, Kennedy S, Al-Thani $G$, et al. A novel missense mutation in the galactosyltransferase-I (B4GALT7) gene in a family exhibiting facioskeletal anomalies and Ehlers-Danlos syndrome resembling the progeroid type. Am J Med Genet A. 2004;128A(1):39-45.

25. Guo MH, Stoler J, Lui J, Nilsson O, Bianchi DW, Hirschhorn JN, et al. Redefining the progeroid form of Ehlers-Danlos syndrome: report of the fourth patient with B4GALT7 deficiency and review of the literature. Am J Med Genet A. 2013;161A(10):2519-27.

26. Kresse H, Rosthoj S, Quentin E, Hollmann J, Glossl J, Okada S, et al. Glycosaminoglycan-free small proteoglycan core protein is secreted by fibroblasts from a patient with a syndrome resembling progeroid. Am J Hum Genet. 1987:41(3):436-53.

27. Salter CG, Davies JH, Moon RJ, Fairhurst J, Bunyan D, Foulds N. Further defining the phenotypic spectrum of B4GALT7 mutations. Am J Med Genet A. 2016;170(6):1556-63.

28. Ritelli M, Dordoni C, Cinquina V, Venturini M, Calzavara-Pinton P, Colombi M. Expanding the clinical and mutational spectrum of B4GALT7-spondylodysplastic Ehlers-Danlos syndrome. Orphanet J Rare Dis. 2017;12(1):153.

29. Cartault F, Munier P, Jacquemont ML, Vellayoudom J, Doray B, Payet C, et al. Expanding the clinical spectrum of B4GALT7 deficiency: homozygous $p$. R270C mutation with founder effect causes Larsen of Reunion Island syndrome. Eur J Hum Genet. 2015;23(1):49-53.

30. Malfait F, Kariminejad A, Van Damme T, Gauche C, Syx D, Merhi-Soussi F, et al. Defective initiation of glycosaminoglycan synthesis due to B3GALT6 mutations causes a pleiotropic Ehlers-Danlos-syndrome-like connective tissue disorder. Am J Hum Genet. 2013;92(6):935-45.
31. Van Damme T, Pang X, Guillemyn B, Gulberti S, Syx D, De Rycke R, et al. Biallelic B3GALT6 mutations cause spondylodysplastic Ehlers-Danlos syndrome. Hum Mol Genet. 2018;27(20):3475-87.

32. Baasanjav S, Al-Gazali L, Hashiguchi T, Mizumoto S, Fischer B, Horn D, et al. Faulty initiation of proteoglycan synthesis causes cardiac and joint defects. Am J Hum Genet. 2011;89(1):15-27.

33. Alazami AM, Al-Qattan SM, Faqeih E, Alhashem A, Alshammari M, Alzahrani $F$, et al. Expanding the clinical and genetic heterogeneity of hereditary disorders of connective tissue. Hum Genet. 2016;135(5):525-40.

34. Bloor S, Giri D, Didi M, Senniappan S. Novel splicing mutation in B3GAT3 associated with short stature, GH deficiency, Hypoglycaemia, developmental delay, and multiple congenital anomalies. Case reports in genetics. 2017;2017:3941483.

35. Budde BS, Mizumoto S, Kogawa R, Becker C, Altmuller J, Thiele H, et al. Skeletal dysplasia in a consanguineous clan from the island of Nias/ Indonesia is caused by a novel mutation in B3GAT3. Hum Genet. 2015;134(7):691-704.

36. Job F, Mizumoto S, Smith L, Couser N, Brazil A, Saal H, et al. Functional validation of novel compound heterozygous variants in B3GAT3 resulting in severe osteopenia and fractures: expanding the disease phenotype. BMC Med Genet. 2016;17(1):86.

37. Jones KL, Schwarze U, Adam MP, Byers PH, Mefford HC. A homozygous B3GAT3 mutation causes a severe syndrome with multiple fractures, expanding the phenotype of linkeropathy syndromes. Am J Med Genet A. $2015 ; 167 A(11): 2691-6$.

38. von Oettingen JE, Tan WH, Dauber A. Skeletal dysplasia, global developmental delay, and multiple congenital anomalies in a 5-year-old boy-report of the second family with B3GAT3 mutation and expansion of the phenotype. Am J Med Genet A. 2014;164A(6):1580-6.

39. Yauy K, Tran Mau-Them F, Willems M, Coubes C, Blanchet P, Herlin C, et al B3GAT3-related disorder with craniosynostosis and bone fragility due to a unique mutation. Genetics in medicine : official journal of the American College of Medical Genetics. 2018;20(2):269-74.

40. Pedersen LC, Darden TA, Negishi M. Crystal structure of beta 1,3glucuronyltransferase I in complex with active donor substrate UDP-GICUA. J Biol Chem. 2002;277(24):21869-73.

41. Gulberti S, Lattard V, Fondeur M, Jacquinet JC, Mulliert G, Netter $P$, et al. Phosphorylation and sulfation of oligosaccharide substrates critically influence the activity of human beta1,4-galactosyltransferase 7 (GalT-I) and beta1,3-glucuronosyltransferase I (GlCAT-I) involved in the biosynthesis of the glycosaminoglycan-protein linkage region of proteoglycans. J Biol Chem. 2005:280(2):1417-25.

42. Ouzzine M, Gulberti S, Levoin N, Netter P, Magdalou J, Fournel-Gigleux S. The donor substrate specificity of the human beta 1,3glucuronosyltransferase I toward UDP-glucuronic acid is determined by two crucial histidine and arginine residues. J Biol Chem. 2002;277(28):25439-45.

43. LaCroix AJ, Stabley D, Sahraoui R, Adam MP, Mehaffey M, Kernan K, et al. GGC repeat expansion and exon 1 methylation of XYLT1 is a common pathogenic variant in Baratela-Scott syndrome. Am J Hum Genet. 2019;104(1):35-44.

44. Lek M, Karczewski KJ, Minikel EV, Samocha KE, Banks E, Fennell T, et al. Analysis of protein-coding genetic variation in 60,706 humans. Nature. 2016:536(7616):285-91.

45. Pettersen EF, Goddard TD, Huang CC, Couch GS, Greenblatt DM, Meng EC, et al. UCSF chimera--a visualization system for exploratory research and analysis. J Comput Chem. 2004;25(13):1605-12.

\section{Publisher's Note}

Springer Nature remains neutral with regard to jurisdictional claims in published maps and institutional affiliations. 